\title{
Comparison of Contraceptive Methods Chosen by Breastfeeding, and Non-Breastfeeding, Women at a Family Planning Clinic in Northern Nigeria
}

\author{
A. Mohammed-Durosinlorun1*, A. Abubakar'1, J. Adze1, S. Bature1, C. Mohammed1, \\ M. Taingson' ${ }^{1}$, A. Ojabo ${ }^{2}$ \\ ${ }^{1}$ Department of Obstetrics and Gynaecology, Faculty of Medicine, Kaduna State University, Kaduna, Nigeria \\ ${ }^{2}$ Department of Obstetrics and Gynaecology, College of Health Sciences, Benue State University, \\ Makurdi, Nigeria \\ Email: *ababdaze@yahoo.com
}

Received 30 November 2015; accepted 29 January 2016; published 1 February 2016

Copyright (C) 2016 by authors and Scientific Research Publishing Inc.

This work is licensed under the Creative Commons Attribution International License (CC BY). http://creativecommons.org/licenses/by/4.0/

(c) (7) Open Access

\section{Abstract}

Introduction: Breast feeding may pose a further challenge to uptake of contraception by possibly restricting use of certain methods for real or perceived risks of side effects. Methodology: A retrospective study was done at the Barau Dikko Teaching Hospital, Kaduna. Available family planning clinic client cards from January $1^{\text {st }}, 2000$ to March 31st, 2014 were retrieved and information collected on demographics, reproductive and menstrual history, contraceptive choices and breast feeding status. Data were analyzed using the statistical package for social sciences (SPSS) version 15. Missing responses were stated and excluded from analysis. Chi square was used as a test of association with significance level established at $p$ value, 0.05 . Results: A total number of 5992 client cards were retrieved. All clients were female and married, and majority of clients aged between 25 - 34 years $(53.1 \%)$, had either completed their secondary education or gone further $(56 \%)$ and were Muslims (52.3\%). Only 2924 women stated that they were currently breastfeeding $(48.8 \%), 1828$ women were not breastfeeding $(30.5 \%)$ and 1240 women $(20.7 \%)$ did not state their breastfeeding status. Younger and more educated women were more likely to be breastfeeding than older women and less educated ones $(p<0.05)$. Only 4636 cards $(77 \%)$ had correctly filled data on the choice of contraceptives chosen by breastfeeding status with 2854 women breast feeding and $1302(45.6 \%)$ chose injectable hormonal contraception, 888 (31.1\%) chose intrauterine contraceptive devices, $484(17 \%)$ chose oral contraceptive pills and $180(6.3 \%)$ chose contraceptive implants. There was no record of condom use or use of permanent methods of contra-

\footnotetext{
"Corresponding author.
}

How to cite this paper: Mohammed-Durosinlorun, A., Abubakar, A., Adze, J., Bature, S., Mohammed, C., Taingson, M. and Ojabo, A. (2016) Comparison of Contraceptive Methods Chosen by Breastfeeding, and Non-Breastfeeding, Women at a Family Planning Clinic in Northern Nigeria. Health, 8, 191-197. http://dx.doi.org/10.4236/health.2016.83022 
ception. Conclusion: Breastfeeding rates were high among women seeking contraception. The pattern of contraception is similar among both breastfeeding and non-breastfeeding women, with injectable contraception being the preferred choice. Awareness should be raised on the safety of a wider variety of contraception available for breastfeeding women.

\title{
Keywords
}

\author{
Contraceptive Methods, Breastfeeding, Northern Nigeria
}

\section{Introduction}

Every year, more than five hundred thousand women lose their lives from complications of pregnancy and childbirth, with more than half of these deaths occurring in the postnatal period, and in sub-Saharan Africa [1]. Nigeria is among countries with high maternal mortality rates, yet contraceptive uptake rates are still relatively low in the country. Only about $10 \%$ of currently married Nigerian women use modern forms of contraception including the lactational amenorrhea method (LAM) [2] [3]. Breast feeding may pose a further challenge to the uptake of contraception by possibly restricting use of certain methods for either real, or perceived risks of possible side effects.

Breast feeding is a widespread and culturally acceptable practice in Nigeria which has undisputed benefits for both the infant and mother [4]. For the baby, the milk has anti-infective properties, ideal nutritional characteristics facilitating infant survival [5] and encourages bonding. For the mother, breastfeeding promotes a quicker recovery after childbirth, and offers some protection from ovarian cancer, breast cancer and type II diabetes [6]. Exclusive breastfeeding is also an effective contraceptive method but food supplementation, the resumption of menstrual bleeding, and reaching the sixth postpartum month while breastfeeding are all associated with increased fertility [4]. The current Nigerian demographic and health survey shows that only 17 percent of children are exclusively breastfed for six months, with early introduction of complementary feeds [3].

In the Philippines, Rous [7] found that some women may actually substitute modern contraception for breast-feeding, leading to the unintended consequence of reducing the rate of breast-feeding. However, others feel that women will usually wean children off breast milk when they get pregnant, so better spacing with modern contraception may actually allow women to breast-feed longer. Hence, contraceptive counseling during breastfeeding extends beyond issues of efficacy, because the selected method must be appropriate for a woman's breastfeeding expectations [8]. In choosing contraceptive methods other than LAM, the non-hormonal methods of contraception such as reversible barrier methods or the copper intrauterine device (IUD), or permanent surgical methods, are usually preferred for breastfeeding mothers. This is because they avoid transfer of hormones into milk which poses a theoretical risk to the infant [9] [10].

Evidence from some systematic reviews suggests that progestogen-only methods of contraception do not adversely affect breastfeeding performance when used during lactation, or adversely affect infant growth, health, or development [11]. A single study of a desogestrel pill, however reported two cases of gynecomastia in exposed infants [11]. Overall, systematic reviews investigating the effects of hormonal contraception (COC, POPs and injectables) on breast milk concluded that there is insufficient evidence to establish if hormonal contraception indeed has any effect on breast milk quantity or quality, and provide some reassurance that hormonal contraception does not have an adverse effect on infant growth or development [10].

Timing is also important when initiating hormonal contraception. The WHO recommends that if combined hormonal methods are going to be utilized, they should not be initiated until at least 6 months postpartum after breastfeeding skills and patterns are already well established [12]. However, progesterone only methods may be initiated after 6 weeks [12]. Hormonal methods maybe discouraged in circumstances where there is already existing low milk supply or history of lactation failure, history of breast surgery, multiple births (twins, triplets), preterm birth or compromised health of mother and/or baby [8].

This study was done to determine how breastfeeding affects the contraceptive choices of women in this environment and to make relevant recommendations on how to increase uptake of appropriate methods of contraception in this group of women, also to see if there are any differences in the contraceptive uptake by breastfeeding status. 


\section{Methodology}

This was a retrospective study done at the Barau Dikko Teaching Hospital (BDSH), a 240-bed secondary/tertiary Care hospital located in Kaduna and catering for the metropolis and its environs. We retrieved all available client cards from the family planning clinic from January $1^{\text {st }}, 2000$ to March $31^{\text {st }}, 2014$. Information was collected to determine the contraceptive choices of breastfeeding women at first visit and subsequently, as well as data on demographics, reproductive and menstrual history. Approval for the study was gotten from hospital authorities and there was no risk to clients whose information was kept confidential. Data was analyzed using the statistical package for social sciences (SPSS) version 15. Missing responses were stated as such and excluded from analysis. Chi square was used as a test of association with significance level established at $p$ value, 0.05.

\section{Results}

A total number of 5,992 client cards were retrieved and all clients were female and married. Majority of clients were aged between 25 - 34 years (53.1\%), had either completed their secondary education or gone further (56\%) and were Muslims (52.3\%). Demographic characteristics are shown in Table 1.

Table 1. Demographic characteristics of family planning clients.

\begin{tabular}{|c|c|c|}
\hline Variable Age in years & Frequency & Percent (\%) \\
\hline$<20$ & 131 & 2.2 \\
\hline $20-24$ & 985 & 16.4 \\
\hline $25-29$ & 1501 & 25.1 \\
\hline $30-34$ & 1680 & 28.0 \\
\hline $35-39$ & 1053 & 17.6 \\
\hline $40-44$ & 455 & 7.6 \\
\hline $45-49$ & 139 & 2.3 \\
\hline$\geq 50$ & 47 & 0.8 \\
\hline Missing & 1 & 0.0 \\
\hline \multicolumn{3}{|l|}{ Education } \\
\hline None & 595 & 9.9 \\
\hline Some secondary & 685 & 11.4 \\
\hline Some primary & 409 & 6.8 \\
\hline \multicolumn{3}{|l|}{ Completed secondary } \\
\hline or more & 3410 & 56.9 \\
\hline Completed primary & 861 & 14.4 \\
\hline Missing & 32 & 0.5 \\
\hline \multicolumn{3}{|l|}{ Religion } \\
\hline Islam & 3135 & 52.3 \\
\hline Christianity & 2278 & 38.0 \\
\hline Others & 33 & 0.6 \\
\hline Missing & 546 & 9.1 \\
\hline Total & 5992 & 100 \\
\hline
\end{tabular}


Out of the total, 2924 women stated that they were currently breastfeeding (48.8\%), 1828 women were not breastfeeding (30.5\%) and 1240 women 920.7\%) did not state their breastfeeding status. Table 2 shows a comparison of demographic characteristics between breastfeeding and non-breastfeeding women. Younger and more educated women were more likely to be breastfeeding than older women and less educated ones $(p<0.05)$.

However, only 4636 cards (77\%) had correctly filled data on the choice of contraceptives chosen by breastfeeding and non-breastfeeding women. There were more women breast feeding (2854: 61.6\%) their children and seeking contraception than women who were not currently breastfeeding (1782: 38.4\%). On the whole (irrespective of breastfeeding status), 2126 women (45.9\%) choose injectable contraception, 1704 women (36.8\%) choose copper-T intrauterine devices, 591 women (12.7\%) choose oral contraceptive pills and 215 women (45.9\%) choose implants for contraception. While among the 2854 women breast feeding, 1302 (45.6\%) choose injectable hormonal contraception, 888 (31.1\%) choose intrauterine contraceptive devices, 484 (17\%) choose oral contraceptive pills and 180 (6.3\%) choose contraceptive implants. There was no record of condom use or use of permanent methods of contraception.

The pattern of preferred methods of contraception was similar among both breast feeding and non-breastfeeding women; uptake of injectable contraception being the highest followed by intrauterine devices, oral contraceptive pills then contraceptive implants (Figure 1). However, there was still a significant difference among both groups; breastfeeding women were more likely to take up all the various methods of contraception than non-breastfeeding women (Pearson Chi Square $=212.260, \mathrm{df}=3, p$ value $=0.000)($ Table 3$)$.

Table 2. Comparison of demographic characteristics of breastfeeding and non-breastfeeding women.

\begin{tabular}{|c|c|c|}
\hline VARIABLE & BREASTFEEDING Frequency (Row \%) & NON-BREASTFEEDING Frequency (Row \%) \\
\hline \multicolumn{3}{|l|}{ Age in years $(n=4751)$} \\
\hline$<20$ & $80(85.1)$ & $14(14.9)$ \\
\hline $20-24$ & 777 (97.9) & $17(2.1)$ \\
\hline $25-29$ & $857(74.7)$ & $290(25.3)$ \\
\hline $30-34$ & $813(60.9)$ & $522(39.1)$ \\
\hline $35-39$ & 313 (38.9) & $492(61.1)$ \\
\hline $40-44$ & $84(20.7)$ & $321(79.3)$ \\
\hline $45-49$ & $0(0)$ & $130(100)$ \\
\hline$\geq 50$ & $0(0)$ & $41(100)$ \\
\hline \multicolumn{3}{|c|}{$\chi^{2}=1282.062, \mathbf{d f}=7, p=0.000$} \\
\hline \multicolumn{3}{|l|}{ Education $(n=4724)$} \\
\hline None & $279(60.0)$ & $186(40.0)$ \\
\hline Some primary & $127(44.7)$ & $157(55.3)$ \\
\hline Completed primary & $258(46.3)$ & $299(53.7)$ \\
\hline Some secondary & $392(79.4)$ & $102(20.6)$ \\
\hline \multirow[t]{2}{*}{ Completed secondary } & $1850(63.3)$ & $1074(36.7)$ \\
\hline & or more & \\
\hline \multicolumn{3}{|c|}{$\chi^{2}=158.816, \mathrm{df}=4, p=0.000$} \\
\hline \multicolumn{3}{|l|}{ Religion $(n=4690)$} \\
\hline Islam & $2074(72.6)$ & $782(27.4)$ \\
\hline Christianity & $803(44.6)$ & 999 (55.4) \\
\hline Others & $32(100.0)$ & $0(0.0)$ \\
\hline \multicolumn{3}{|c|}{$\chi^{2}=389.000, \mathbf{d f}=2, p=0.000$} \\
\hline \multicolumn{3}{|l|}{ Last child birth $(\mathrm{n}=4177)$} \\
\hline$<6$ months & 855 (86.5) & $133(13.5)$ \\
\hline 6 - 15 months & 1726 (85.9) & $284(14.1)$ \\
\hline$>15$ months & $129(10.9)$ & $1050(89.1)$ \\
\hline$\chi^{2}=$ 2097.426, $\mathbf{d f}=2, p=0$. & & \\
\hline
\end{tabular}

( $\mathrm{n}=$ number of valid responses, $\chi^{2}=$ chi square, $\mathrm{df}=$ degree of freedom, $p=p$ value). 


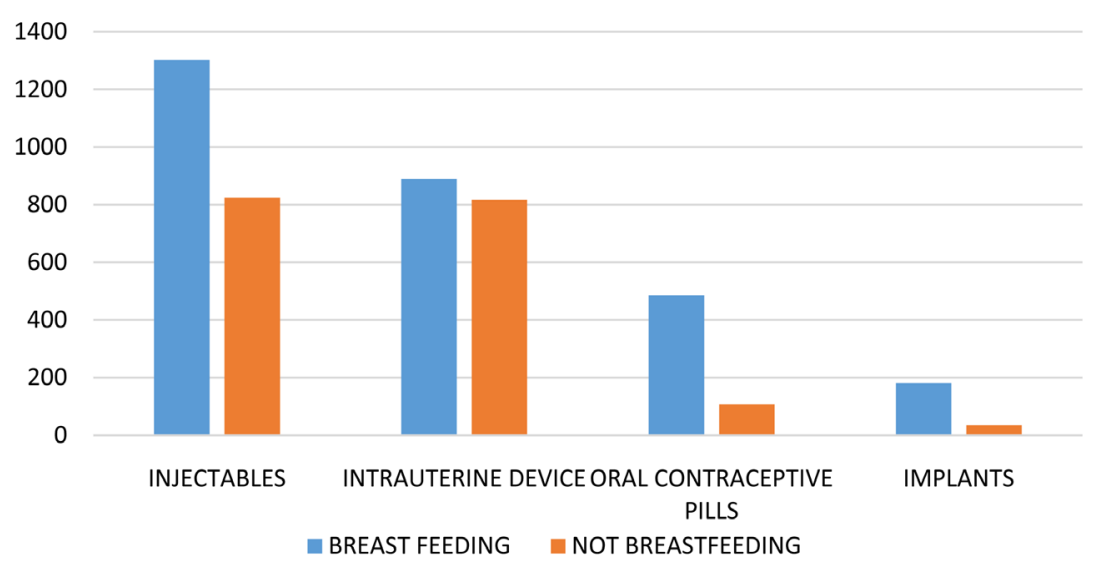

Figure 1. Chart comparing contraceptive methods chosen by breastfeeding and non-breastfeeding women.

Table 3. Cross tabulation of forms on contraception chosen by breast feeding and non-breastfeeding women.

\begin{tabular}{ccccc}
\hline & Injectables & Intrauterine device (copper-T) & Oral contraceptive pills & Implants \\
\hline Breast feeding & $1302(61.2 \%)$ & $888(52.1 \%)$ & $484(81.9 \%)$ & $180(83.7 \%)$ \\
Not breast feeding & $824(38.8 \%)$ & $816(47.9 \%)$ & $107(18.1 \%)$ & $35(16.3 \%)$ \\
Total & $2126(100 \%)$ & $1704(100 \%)$ & $591(100 \%)$ & $215(100 \%)$ \\
\hline
\end{tabular}

(Pearson Chi Square $=212.260, \mathrm{df}=3, p$ value $=0.000)$.

\section{Discussion}

The breastfeeding rate in this population of women attending the family planning clinic was $48 \%$ and breastfeeding was commoner among those that were younger and more educated. The 2013 Nigerian Demographic and Health Survey showed that $96 \%$ of children aged 6 - 8 months, 91\% of children aged 9-11 months and 35\% of children aged 20 - 23 months in Nigeria are being breastfed [3].

Injectable contraception was the first method of choice chosen by both breast feeding and non-breastfeeding mothers. This finding is consistent with national surveys which showed that among the modern methods of contraception, injectables ( 3 percent), male condoms ( 2 percent), and the pill (2 percent) are the most common methods being used [3]. Anyebe et al. [13] also found injectables to be the commonest form of contraception used by $30.2 \%$ of 96 respondents. Other authors also found hormonal methods (32\%) and condoms (23\%) to be the most favourite contraceptive methods during the postpartum period [14] [15]. Injectable contraception such as Depot provera (DMPA) and Noristerat are suitable for women who want a reliable, reversible form of contraception, and has numerous advantages such as; better compliance than like oral contraceptives which requires daily vigilance, unlike barrier contraceptives it is independent of the time of intercourse and It may be more appealing than contraceptive implant or intrauterine devices, as no intervention is required to remove it [16] [17]. It is a suitable choice in the postpartum period and in breastfeeding mothers where oestrogen therapy in the combined oral contraceptive pills may be less desired [16] [17]. Another advantage of the choice of injectable contraception in our environment may be that this form of contraception is not so "obvious" to husbands, especially if the husband may not approve and the woman is still desirous of contraception.

All the other methods chosen are suitable for breast feeding women except for combined hormonal contraception which is classified as a category 4 (unacceptable health risk) for all postpartum women, regardless of breastfeeding status, for the first 21 days [18] due to the risk of thromboembolism.

Condoms have also been found to be popular postpartum contraceptives in a study in Nigeria [3] [19] and has the added advantage of protection against sexually transmitted infections (STI) including HIV/AIDS but was not recorded in this study. This may be because condoms are more commonly distributed free at the STI clinic also within the hospital and in close proximity to the family planning clinic. So while women may be using condoms, the documentation is missed at the family planning clinic. It may be for the same reason that there are no records of permanent methods of contraception (which is more likely to be captured in the theater) documented, though this is a very unpopular choice in Nigeria [3] [13]. 


\section{Conclusion and Recommendations}

Breastfeeding rates are high among women seeking contraception. The pattern of contraception is similar among both breastfeeding and non-breastfeeding women, with injectable contraception being the preferred choice. Awareness should be raised on the safety of a wider variety of contraception available for breastfeeding women.

\section{Limitation of Study}

This was a retrospective study and some data was lost as they were not properly recorded. Also this made it difficult to delve deeper into reasons affecting choices women made regarding contraceptive methods chosen.

\section{Declaration of Interests}

None.

\section{References}

[1] Ronsman, C. and Graham, W.J. (2006) On Behalf of the Lancet Maternal Survival Steering Group. Maternal Mortality: Who, When, Where, and Why? Maternal Survival. Lancet, 368, 1189-1200.

[2] Mohammed-Durosinlorun, A. and Krishna, R. (2014) A Quantitative Survey on the Knowledge, Attitudes and Practices on Emergency Contraceptive Pills among Adult Female Students of a Tertiary Institution in Kaduna, Nigeria. Primary Health Care, 4, 148.

[3] National Population Commission (NPC) [Nigeria] and ICF International (2014) Nigeria Demographic and Health Survey 2013. National Population Commission and International ICF, Abuja.

[4] King, J. (2007) Contraception and Lactation. Journal of Midwifery and Women's Health, 52, 614-620. http://dx.doi.org/10.1016/j.jmwh.2007.08.012

[5] Dada, O.A., Akesode, F.A., Olanrewaju, D.M., Sule-Odu, O., Fakoya, T.A., Oluwole, F.A., Odunlami, B.V. and WHO (2002) Infant Feeding and Lactational Amennorrhea in Sagamu, Nigeria. Africa Journal of Reproductive Health, 6, 39-50. http://dx.doi.org/10.2307/3583129

[6] National Health and Medical Research Council (2012) Infant Feeding Guidelines. National Health and Medical Research Council, Canberra.

[7] Rous, J.J. (2001) Is Breast-Feeding a Substitute for Contraception in Family Planning? Demography, 38, 497-512. http://dx.doi.org/10.1353/dem.2001.0037

[8] Berens, P., Labbok, M. and The Academy of Breastfeeding Medicine (2015) ABM Clinical Protocol \#13: Contraception during Breastfeeding, Revised 2015. Breastfeeding Medicine, 10, 3-12. http://dx.doi.org/10.1089/bfm.2015.9999

[9] Truitt, S.T., Fraser, A.B., Grimes, D.A., Gallo, M.F. and Schulz, K.F. (2003) Combined Hormonal versus Nonhormonal versus Progestin-Only Contraception in Lactation. Cochrane Database of Systematic Reviews, 2, Article ID: CD003988.

[10] FFPRHC Guidance (2004) Contraceptive Choices for Breastfeeding Women. Journal of Family Planning and Reproductive Health Care, 30, 181-189. http://dx.doi.org/10.1783/1471189041261429

[11] Kapp, N., Curtis, K. and Naanda, K. (2010) Progestogen-Only Contraceptive Use among Breastfeeding Women: A Systematic Review. Contraception, 82, 17-37 http://dx.doi.org/10.1016/j.contraception.2010.02.002

[12] Queenan, J.T. (2004) Contraception and Breastfeeding. Clinical Obstetrics and Gynecology, 47, 734-739. http://dx.doi.org/10.1097/01.grf.0000139710.63598.b1

[13] Anyebe, E.E., Olufemi, S.K. and Lawal, H.R.N. (2014) Contraceptive Use among Married Women in Zaria, Northwest Nigeria. Research on Humanities and Social Sciences, 4, 69-75.

[14] Cwiak, C., Gellasoh, T. and Zieman, M. (2004) Peripartum Contraceptive Attitudes and Practices. Contraception, 70, 383-386. http://dx.doi.org/10.1016/j.contraception.2004.05.010

[15] Omolulu, A. and Okunowo, A. (2009) Intended Postpartum Contraceptive Use among Pregnant and Puerperal Women at a University Teaching Hospital. Archives of Gynecology and Obstetrics, 280, 987-992. http://dx.doi.org/10.1007/s00404-009-1056-6

[16] Faculty of Sexual and Reproductive Healthcare (2014) Progestogen-Only Injectable Contraception Clinical Guidiance.

[17] NICE Clinical Guideline (2014) Long-Acting Reversible Contraception Update. 
[18] CDC US (2010) Medical Eligibility Criteria for Contraceptive Use: Adapted from the World Health Organization Medical Eligibility Criteria for Contraceptive Use. 4th Edition, MMWR, No. RR-4, 59.

[19] Adegbola, O. and Okunowo, A. (2009) Intended Postpartum Contraceptive Use among Pregnant and Puerperal Women at a University Teaching Hospital. Archives of Gynecology and Obstetrics, 280, 987-992.

http://dx.doi.org/10.1007/s00404-009-1056-6 